\title{
A secured automated bimodal biometric electronic voting system
}

\author{
Kennedy Okokpujie ${ }^{1}, J^{\prime}$ hn Abubakar ${ }^{2}$, Samuel John $^{3}$, Etinosa Noma-Osaghae $^{4}$, Charles Ndujiuba $^{5}$, \\ Imhade Princess Okokpujie ${ }^{6}$ \\ ${ }^{1,2,4}$ Department of Electrical and Information Engineering, Covenant University, Ota, Nigeria \\ ${ }^{3}$ Department of Electrical and Electronic Engineering, Nigerian Defence Academy, Kaduna, Nigeria \\ ${ }^{5}$ Department of Electrical and Electronic Engineering, Air Force Institute of Technology, Kaduna, Nigeria \\ ${ }^{6}$ Department of Mechanical Engineering, Covenant University, Ota, Nigeria
}

\begin{tabular}{|c|c|}
\hline Article Info & ABSTRACT \\
\hline Article history: & Insecurity, rigging and violence continue to mar electoral processes in \\
\hline Received Oct 16, 2020 & $\begin{array}{l}\text { developing nations. It has been difficult to enforce security and transparency } \\
\text { in the voting process. This paper proposes a secure and automated bimodal }\end{array}$ \\
\hline Revised Jan 2, 2021 & voting system. The system uses three security layers, namely, a unique ID \\
\hline Accepted Jan 12, 2021 & $\begin{array}{l}\text { code, a token passcode that expires every five minutes and biometrics (iris } \\
\text { and fingerprint). A scanner captures the fingerprint and iris of eligible voters. }\end{array}$ \\
\hline Keywords: & $\begin{array}{l}\text { The fingerprint and iris images stored along with the corresponding } \\
\text { particulars in a database. The software implemented is a net managed code }\end{array}$ \\
\hline $\begin{array}{l}\text { Bimodal biometric } \\
\text { Electronic voting } \\
\text { Fingerprint }\end{array}$ & $\begin{array}{l}\text { in C\#. The result of this system shows the system is transparent, fast and } \\
\text { fraud-free. The proposed method had a failure to enroll (FTE) and a failure to } \\
\text { capture (FTC) of zero. }\end{array}$ \\
\hline
\end{tabular}

Iris

Secure database

This is an open access article under the $\underline{C C B Y-S A}$ license.

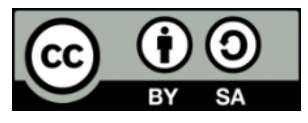

Corresponding Author:

Kennedy Okokpujie

Department of Electrical and Information Engineering

Covenant University

Km 10 Idiroko Road, Ota, Ogun State, Nigeria

Email: kennedy.okokpujie@ covenantuniversity.edu.ng

\section{INTRODUCTION}

Voting is the most indispensable asset in any democratic country. It is the process of selecting a suitable candidate to lead the people. A democratic nation is the people's country. Democratic government can only be right when there is provision for a trustworthy and secured electoral process [1]. E-voting is an emerging technology that has improved the traditional method of voting [2]. E-voting with the use of biometric has provided a more secure way of voting in a democratic country compared to the traditional voting where papers are used, and voting is insecure [3-5]. Biometric is a physical and biological quality of an individual which is different for every person [6-7]. There are different types of biometric traits among which are facial recognition, Fingerprint, iris recognition, and palm print [8-10].

Rigging of elections are still possible in today democratic process because one person could votes more than one. Most of the system are not biometrically automated and as such would not be able to identify the imposters, who possesses more than one voter's card and as such could do multiply voting. With the application of bimodal biometric, the traits are unique to that right person only and can easily detects and stop imposters.

This paper proposes a web-based and secured automatic bimodal biometric electronic voting system. The biometrics was used to identify individuals that are eligible to vote; the proposed method 
provided likely voters with a unique ID and a token code. The proposed electronic voting system also provided a dependable, transparent. It secured electronic voting system that eliminated the possibility of impersonation by using two biometric traits and automating the voting process to save time. The resulting system had the propensity to improve the integrity factor of the voting process by making it fast, transparent and robust [11-15].

The [16], developed a web-based voting system using fingerprint recognition. The design proposed was used for a university's presidential election. Four candidates and 40 voters registered for the election. Each voter's particulars, biometric and regular were collected and stored in a database. During the election, the registered voters were able to cast votes over the internet. The software used to implement the e-voting system was written in C\#.

In [17], a framework was proposed for a low cost secured electronic voting system based on facial recognition using local binary pattern (LBP) for extracting facial feature characterization in texture format and chi-square for image classification. A two-level security using a passcode and biometric (face) was implemented. The proposed system was web-based. The system eliminated the need to wait for the vote to be counted by providing a page that shows the live count of the election every second, thereby minimizing votecounting time.

F. I. Hazzaa, S. Kadry, and O. K. Zein [18] proposed a framework to ensure secured identification and authentication processes for voters using Fingerprint biometric. The main aim was to eliminate fake voters, vote repetition and provide more transparency. The Fingerprint was used for the identification of the individual. In the proposed system, a network connection and electoral officers were not needed. The electronic voting machine was designed to direct eligible voters on how to cast votes without the need of a network connection or an attending electoral officer. Olaniyi et al. in [19] designed a secure electronic voting system using fingerprint biometric and the crypto- watermarking approach. The fingerprint biometric was used for the identification of the individual. The system also used an encryption standard (AES) cryptographic algorithm to improve the integrity of the proposed method [20-25].

The paper is organized; thus, a thorough expository on the methodology used for the study is given in section three (Methodology). The results of the study are elucidated in section four (Results and Discussion).

\section{RESEARCH METHOD}

The proposed electronic voting system centred on two trait biometrics, the fingerprint and the iris. The system design improves the overall security and credibility of electoral processes. The proposed method is designed and implemented using an Irishield-UART MO2120, a Digital Persona U\&U 4500 fingerprint scanner and a personal computer. The biometric sensors were used to acquire the wanted biometric trait, and the personal computer was used as a development environment to create the database and software used to cast votes. Figure 1 shows the functional block diagram of the proposed voting system.

The proposed voting system was programmed using C\# language. SQL server was used to create the electronic voting database. The database created had three tables; the candidate table for the candidate data, the voter table for the voter (the eligible voters) information with their biometric details and the vote table for vote counting. Visual studio 2017 was the integrated development environment (IDE) used to implement the voting system. Visual studio has a lot of unique that made it easy to integrate various plugins. The codes used in C\# were long. Visual studio made it possible to find a code amid lots of other systems.

During the registration phase, various information was required from the individual or user such as username, state of origin, password, and also validation of birth certificate. The registration was used to create an online account for each eligible voter. Immediately after registration, individuals are given a unique code. The flow chart in Figure 2 shows how the registration process was carried out. Figure 3 shows the online registration page of the proposed voting system.

The algorithm for the registration process is:

Step 1: Initialize

Step 2: Proceed to webpage

Step 3: Proceed to registration

Step 4: Input your person's details

Step 5: Upload your picture and birth certificate

Step 6: Are you eligible to vote

Go to step 7 Else

Go to step 1

Step 7: Unique ID sent via mail

Step 8: Press finish to redirect to home page

Int J Artif Intell, Vol. 10, No. 1, March 2021: $1-8$ 
The next phase after registration was the biometric enrolment. Iris and fingerprint samples were acquired from eligible voters using the Irishield-UART MO2120 and the Digital Persona U\&U 4500 fingerprint scanner, respectively. The information (biometric images) got from each eligible voter were stored along with the voter's particulars in the database.

Once an individual enrols in the system, the user has the privilege to vote. Authentication refers to as identification implies a one-to-one match. During the authentication stage, the biometric sample of the user is compared to the previously stored information. Figure 4 shows the flowchart of the voting process. The user is first prompted to provide a unique ID and token password.

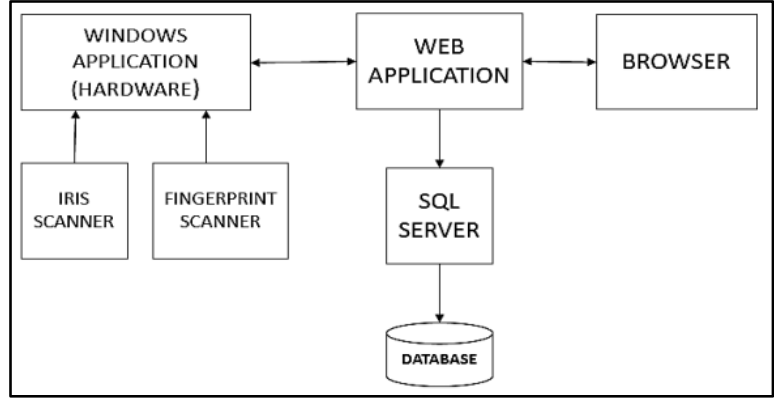

Figure 1. Functional block diagram of the secured biometric electronic voting system

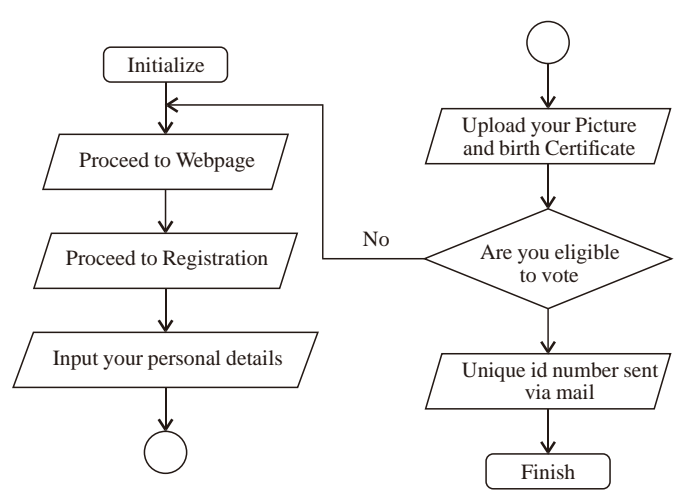

Figure 2. Flow chart for the registration process

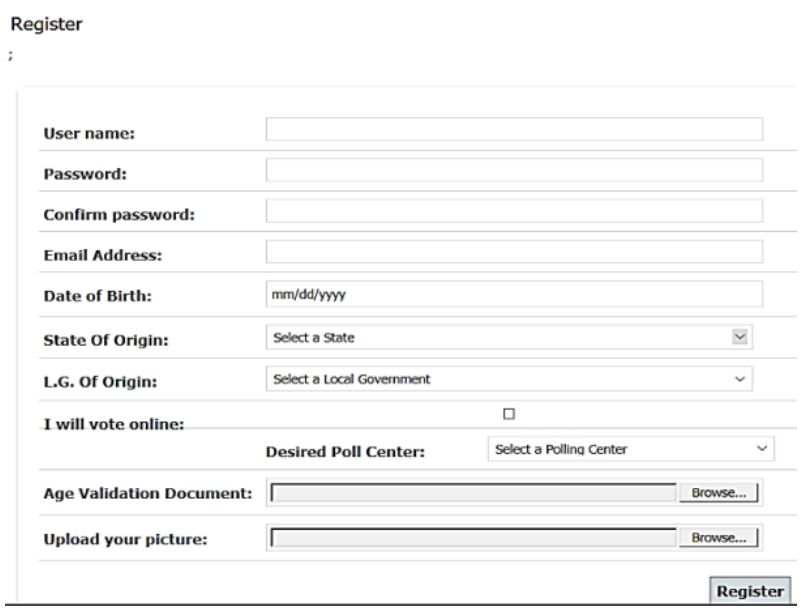

Figure 3. The webpage for the registration process

The algorithm of this process described by Figure 4 is:

Step 1: Initialize

Step 2: $\log$ in

Step 3: Is login true

Go to step 4

Else

Go to step 1

Step 4: Vote

Step 5: Pick your candidate

Step 6: Authenticate your biometric Step 7: Input your iris

Step 8: Does iris match Go to step 9

Else

Go to step 7

Step 9: Input your fingerprint Step 10: Does fingerprint match Go to step 11

Else 
Go to step 9

Step 11: Input your unique ID code

Step 12: Is ID true

Go to step 13

Else

Go to step 11

Step 13: Select a state to cast your vote

Step 14: Select the party of your choice

Step 15: Input your token password

Step 16: Is token password true

Go to step 17

Else

Go to step 15

Step 17: Vote counted

Step 18: End

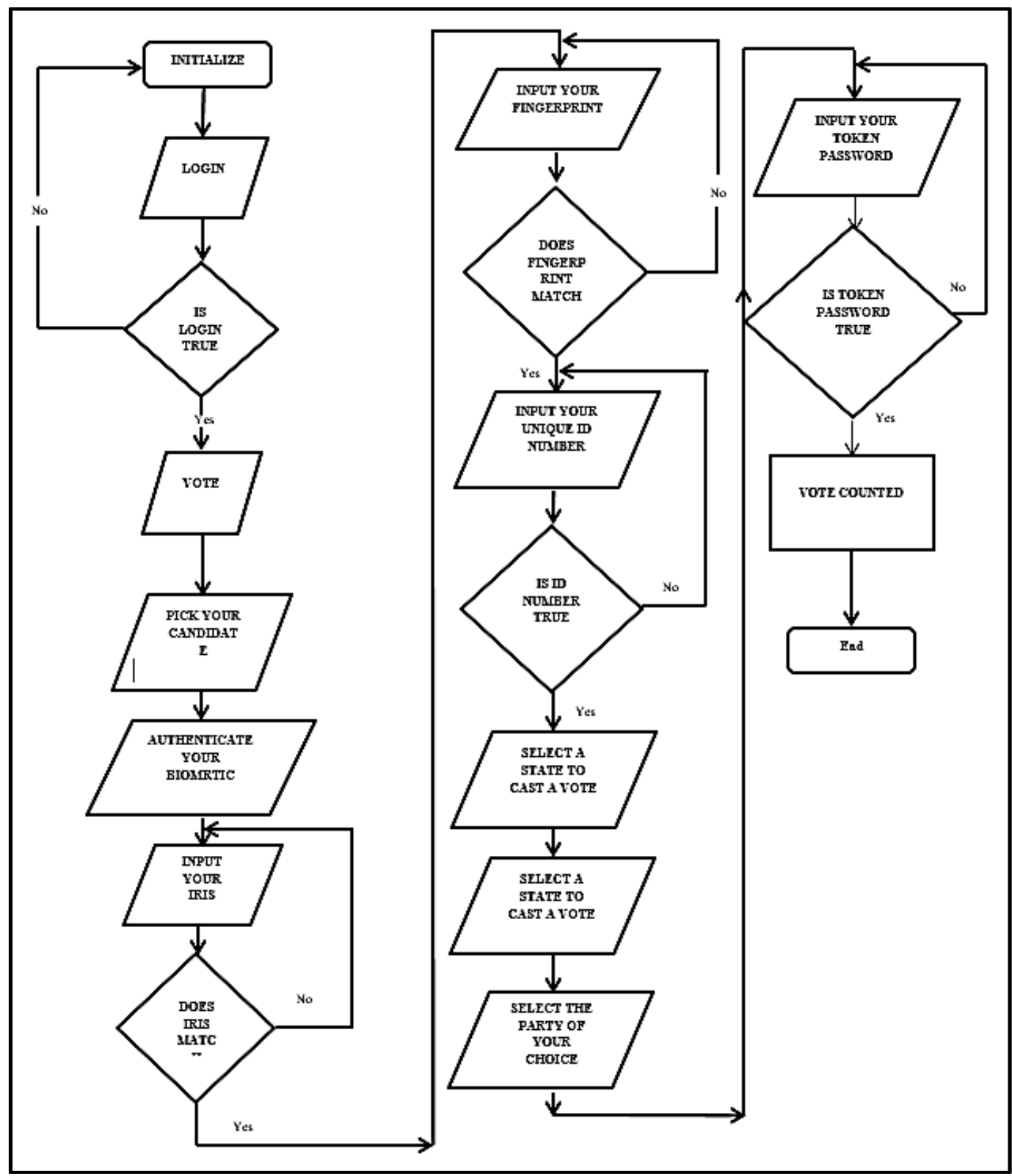

Figure 4. Flow chart of the proposed electronic voting system 
The biometric authentication stage requires the voter to provide biometric input (iris and fingerprint). The biometric input is compared to the biometric information saved on the database (i.e. the system performs a one-to-many authentication) as shown in Figures 5-6.

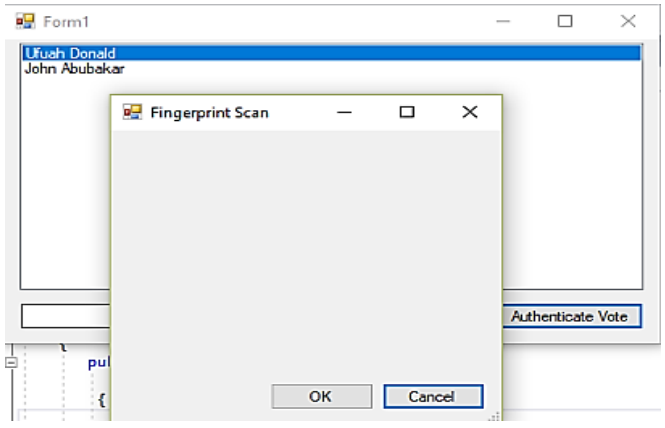

Figure 5. Fingerprint authentication

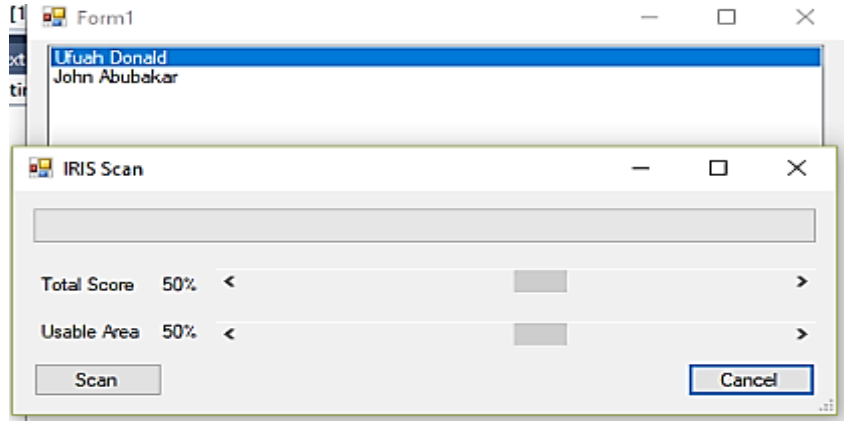

Figure 6. Iris authentication

A correct unique ID, password token and a match for the biometric information provided qualifies a user to cast a ballot. An administrator can $\log$ in to the web-based platform to monitor the election and also view the total result, as shown in Figure 7.

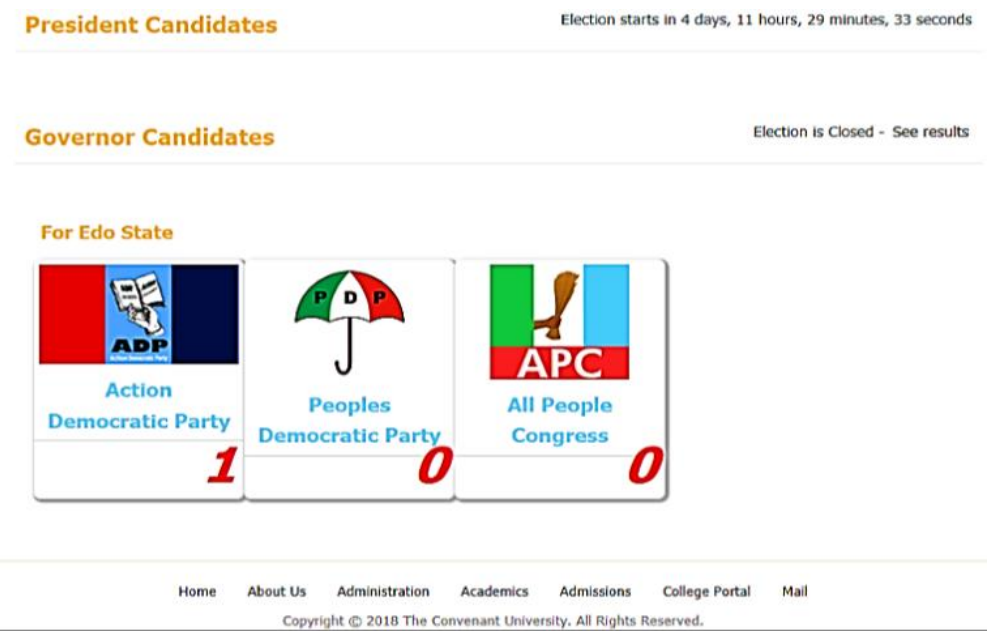

Figure 7. Vote counted immediately after voting

\section{RESULTS AND DISCUSSION}

After testing the functionality of the system, registration began, and various students registered. A database of multiple users was developed, as shown in Figure 8. The detail of users activities can be monitor from the administrator's end.

It was discovered that the performance of the biometric system could be influenced by environmental factors during the image acquisition stage and the performance factors of image quality algorithm used. In order to measure the accuracy and performance of the biometric system, the following performance metrics were used:

- $\quad$ Time of enrolment (TOF): This was the time it took for an individual to enrol the enrolment time during voting was $5 \mathrm{ec}$.

- $\quad$ Failure to enrol (FTE): This occurs when the iris scanner and the fingerprint sensor consider a data invalid during enrolment. During the measurement analysis, the system enrolled everybody. The FTE is zero (0)

- $\quad$ Failure to capture (FTC): This occurs when the sensors fail to capture the data presented by the individual (the fingerprint and the iris). The FTC is zero (0). 


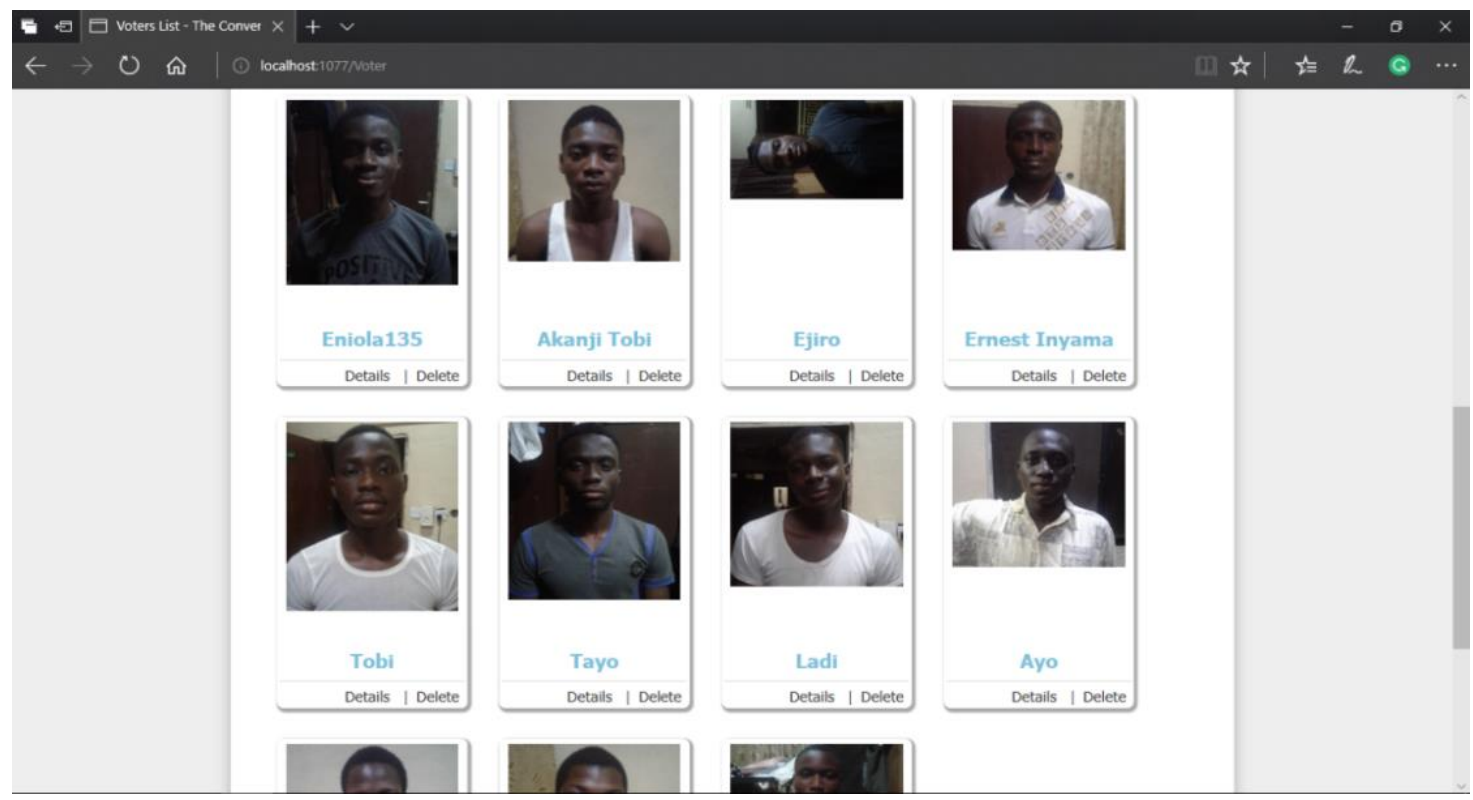

Figure 8. A sample of the enrolled users

\section{CONCLUSION}

The primary objectives of this study were achieved as the electronic voting system using bimodal biometric eliminated fraud and the possibility of voting more than once. The implementation of a three-level security bimodal biometric e-voting system was successful. It was web-based and allowed only one time voting for each eligible user.

\section{ACKNOWLEDGEMENTS}

This paper was funded by the Covenant University Center for Research, Innovation, and Discovery (CUCRID), Ota, Ogun State, Nigeria.

\section{REFERENCES}

[1] K. O. Okokpujie, E. Noma-Osaghae, O. J. Okesola, S. N. John, and O. Robert, "Design and implementation of a student attendance system using iris biometric recognition," in 2017 International Conference on Computational Science and Computational Intelligence (CSCI): IEEE, pp. 563-567, 2017. DOI 10.1109/CSCI.2017.96.

[2] K. O. Okokpujie, S. N. John, E. Noma-Osaghae, C. Ndujiuba, and I. P. Okokpujie, "An Enhanced Voters Registration and Authentication Application Using Iris Recognition Technology," International Journal of Civil Engineering and Technology (IJCIET), vol. 10, no. 2, pp. 57-68, 2019.

[3] C. Atuegwu, S. Daramola, K. O. Okokpujie, and E. Noma-Osaghae, "Development of an Improved Fingerprint Feature Extraction Algorithm for Personal Verification," International Journal of Applied Engineering Research, vol. 13, no. 9, pp. 6608-6612, 2018.

[4] M. M. Ali, A. Gaikwad, "Multimodal Biometrics Enhancement Recognition System based on Fusion of Fingerprint and PalmPrint: A Review,” Global Journal of Computer Science and Technology, vol. 16, no. 2, 2016.

[5] S. D. Kumar, P. Vamsikrishna, A. Tyagi, D. Bommisetty, and H. B. Kandala, "Theoretical analysis of voting systems," in Communication and Electronics Systems (ICCES), International Conference on, pp. 1-5, 2016. doi: 10.1109/CESYS.2016.7889932.

[6] K. Okokpujie, et al., "Integration of Iris Biometrics in Automated Teller Machines for Enhanced User Authentication," in International Conference on Information Science and Applications, Springer. pp. 219-228, 2018. DOI:10.1007/978-981-13-1056-0_23.

[7] R. Bhuvanapriya, S. Rozil Banu, P. Sivapriya, and V. K. G. Kalaiselvi, "Smart voting," in 2017 2nd International Conference on Computing and Communications Technologies (ICCCT), pp. 143-147, 2017. doi: 10.1109/ICCCT2.2017.7972261.

[8] E. Noma-Osaghae, O. Robert, C. Okereke, O. J. Okesola, and K. Okokpujie, "Design and Implementation of an Iris Biometric Door Access Control System," in 2017 International Conference on Computational Science and Computational Intelligence (CSCI): IEEE, pp. 590-593, 2017. doi: 10.1109/CSCI.2017.102.

[9] S. Viriri, J. Tapamo, "Iris pattern recognition based on cumulative sums and majority vote methods," International Journal of Advanced Robotic Systems, vol. 14, no. 13, pp. 1-9, 2017. DOI: 10.1177/1729881417703931. 
[10] V. K. Gunjan, P. S. Prasad, and S. Mukherjee, "Biometric Template Protection Scheme-Cancelable Biometrics," in ICCCE 2019, Singapore, pp. 405-411, 2020.

[11] M. A. Febriantono, S. H. Pramono, Rahmadwati, and G. Naghdy, "Classification of multiclass imbalanced data using cost-sensitive decision tree c5.0," IAES Int. J. Artif. Intell., vol. 9, no. 1, pp. 65-72, 2020. DOI: 10.11591/ijai.v9.i1.pp65-72.

[12] K. Okokpujie, O. Modupe, E. Noma-osaghae, O. Abayomi-alli, and E. Oluwawemimo, "A Bimodal Biometric Bank Vault Access Control System,” Int. J. Mech. Eng. Technol. (IJMET), vol. 9, no. 9, pp. 596-607, 2018.

[13] H. Ohmaid, S. Eddarouich, A. Bourouhou, and M. Timouyas, "Iris segmentation using a new unsupervised neural approach,” IAES Int. J. Artif. Intell., vol. 9, no. 1, pp. 58-64, 2020. DOI: 10.11591/ijai.v9.i1.pp58-64.

[14] K. Okokpujie and S. Apeh, "Predictive Modeling of Trait-Aging Invariant Face Recognition System Using Machine Learning," in Information Science and Applications: LNEE Springer, pp. 431-440, 2020. DOI: $10.1007 / 978-981-15-1465-4 \_43$.

[15] K. Okokpujie, S. John, C. Ndujiuba, and E. Noma-Osaghae, "Development of an Adaptive Trait-Aging Invariant Face Recognition System Using Convolutional Neural Networks.pdf," in "Information Science and Applications: LNEE Springer, pp. 411-420, 2020. DOI: 10.1007/978-981-15-1465-4_41.

[16] R. F. L. Chavez, Y. Iano, and V. B. Sablon, "Process of recognition of human iris: Fast segmentation of iris," ed: IEEE, pp. 1-7, 2006.

[17] Neha Kak, Rishi Gupta, Sanchit Mahajan, "Iris Recognition System," International Journal of Advanced Computer Science and Applications (IJACSA), vol. 1, no. 1, pp. 34-40, 2010. DOI: 10.14569/IJACSA.2010.010106.

[18] F. I. Hazzaa, S. Kadry, and O. K. Zein, "Web-Based Voting System Using Fingerprint: Design and Implementation," International Journal of Computer Applications in Engineering Sciences, vol. 2, no. 4, pp. 404409, 2012.

[19] O. M. Olaniyi, T. A. Folorunso, A. Aliyu, and J. Olugbenga, "Design of Secure Electronic Voting System Using Fingerprint Biometrics and Crypto-Watermarking Approach," International Journal of Information Engineering and Electronic Business, vol. 8, no. 5, pp. 9-17, 2016. DOI: 10.5815/ijieeb.2016.05.02.

[20] J. Clerk Maxwell, "A Treatise on Electricity and Magnetism," 3rd ed., vol. 2., Oxford: Clarendon Press, pp.68-73, 1892.

[21] A. V. Naik and H. Virani, "Multimodal Biometric System using Fingerprint, Iris \& Ear," International Journal of Technology and Science, ISSN (Online) 2350-1111, (Print) 2350-1103, vol. IX, no. 1, pp. 40-45, 2016, available: http://i3cpublications.org/Volume\%20IX\%20Issue-1/IJTS-9-1-10-16/IJTS-9-1-10-16.pdf.

[22] F. P. Hjálmarsson, K. H. Gunnlaugur, H. Mohammad, and H. Gísli, "Blockchain-based e-voting system," In 2018 IEEE 11th International Conference on Cloud Computing (CLOUD), pp. 983-986, 2018, doi: 10.1109/CLOUD.2018.00151

[23] R. Krimmer, D. Duenas-Cid, I. Krivonosova, "New methodology for calculating cost-efficiency of different ways of voting: is internet voting cheaper?," Public Money \& Management, Feb 29, vol. 41, no. 1, pp. 17-26, 2020, doi: 10.1080/09540962.2020.1732027.

[24] P. Gaudry, and G. Alexander, "Breaking the encryption scheme of the Moscow internet voting system," In International Conference on Financial Cryptography and Data Security, pp. 32-49, Springer, Cham, 2019, available: https://arxiv.org/pdf/1908.05127.pdf\%22noopener.

[25] Y. Zhou, L. Yining, J. Chengshun, and W. Shulan, "An improved FOO voting scheme using blockchain," International Journal of Information Security 19, no. 3, 303-310, 2020, available: https://doi.org/10.1007/s10207019-00457-8.

\section{BIOGRAPHIES OF AUTHORS}

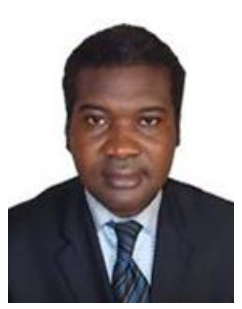

Dr. Kennedy Okokpujie holds a Bachelor of Engineering (B.Eng.) in Electrical and Electronics Engineering, Master of Science (M.Sc.) in Electrical and Electronics Engineering, Master of Engineering (M.Eng.) in Electronics and Telecommunication Engineering and Master of Business Administration (MBA), Ph.D in Information and Communication Engineering, besides several professional certificates and skills. He is currently lecturing with the department of Electrical and Information Engineering at Covenant University, Ota, Ogun State, Nigeria. He is a member of the Nigeria Society of Engineers and the Institute of Electrical and Electronics Engineers (IEEE). His research areas of interest include Biometrics, Artificial Intelligent, and Digital signal Processing. Contact him at kennedy.okokpujie@covenantuniversity.edu.ng

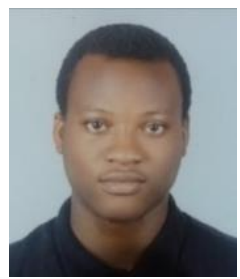

John Abubakar holds a bachelor degree in Electrical and Electronics Engineering from Covenant University and is presently at the concluding stage of his M.Eng in Electrical and Electronics Engineering (Design of power system and machine design) with Covenant University, Ota, Nigeria. 


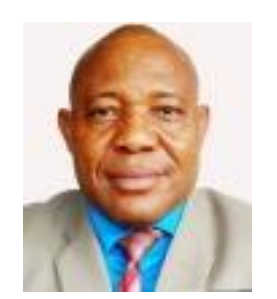

Samuel Ndueso John is a Professor of Computer Systems and Network Engineering. He has his higher education at Donetsk National Technical University, Ukraine where he successfully defended and obtained B.Sc, M.SC, MPhil and Ph.D. degrees in Computer Systems and Network Engineering, specializing in Computer Science, Computing Machines, Complex Systems, Security and Networks in 1993, 1994, 2000 and 2005, respectively. Presently, John is a Professor of Computer Systems and Network Engineering in the Department of Electrical/Electronic Engineering, Faculty of Engineering and Technology, Nigerian Defence Academy, Kaduna, Nigeria. John has acquired valuable knowledge and practical experience in the use of information technology as an enabler of industrial and national development goals. He has a vast knowledge of computing and has applied it in the pursuance of a wide range of indigenous ICT Convergence, Data Efficiency Management, Cyber Security, Cybercrime and Telemedicine solutions.

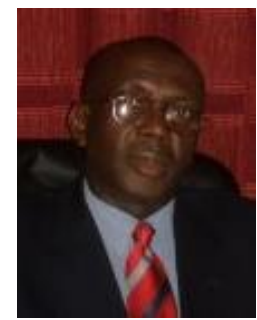

Charles U. Ndujiuba is a professor of Communication Engineering with Air Force Institute of Technology, Nigerian Air Force, Kaduna state, Nigeria. Prof. C. U. Ndujiuba holds a Ph.D. in Electrical \& Electronics Engineering from the University College London (University of London); Master Specialize (Masters with Specialization) in Radio Communications from Ecole Superieure d'Electricite (SUPELEC) France; MSc in Electrical Engineering from the University of Lagos; BSc in Electronics \& Communications Engineering from the London Metropolitan University. Prof. Ndujiuba is a Chartered Electronics Engineer (CEng) and a highly-skilled wireless professional. He has more than 25 years of RF, Microwave, Fixed-line (SDH and PDH), and PMR experience, with considerable international exposure. Prof. Ndujiuba has attended several conferences and published many technical papers in major professional journals. Prior to joining Covenant University Ota Nigeria in 2011, Ndujiuba was the Technical Director of Globe Trunk Ltd UK. His research interests include Monolithic Microwave Integrated Circuits (MMIC), Active Filters, Ultra-Low Noise Amplifiers, Active Devices and Circuits, UWB Transmitter, Modelling \& Simulation, Dielectric Resonator Antennas, and Detection and Collision Avoidance of Unmanned Aerial Vehicles.

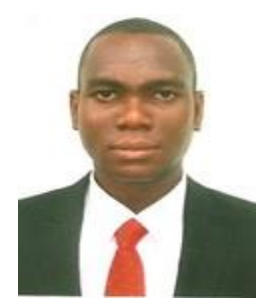

Etinosa Noma-Osaghae holds a master's degree in Electronics and Telecommunication Engineering from the University of Benin. His areas of interest are Telecommunication and Signal Processing.

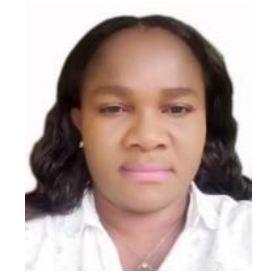

Dr. Okokpujie Imhade Princess, is a researcher/lecturer in the Department of Mechanical Engineering Covenant University, Ota, Ogun State Nigeria. She is currently the Chief Editor to Covenant Journal of Engineering and Technology (CJET), she is also a reviewer to so many international/local journals and conferences. Her areas of research interest are Machine Design, Advanced Manufacturing such as Machining, Tool Wear, Vibration, and Nano-lubricant, Energy Systems, Mathematical Modeling, Optimization, Simulation, and also a Multi-Disciplinary Analysis. She is an active researcher who has authored over 109 peer-reviewed publications. In 2017 to 2019 She was the technical secretary to the International Conference on Engineering for a Sustainable World (ICESW) index in Scopus and ISI data based through the IOPs publisher. She is a Registered Engineer of the Council for the Regulation of Engineering in Nigeria (COREN), a member of the Nigerian Society of Engineers (NSE), and Association of Professional Women Engineers of Nigeria (APWEN). She is currently the Vice Chairman of APWEN Ota Branch in Ogun State. She is one of the top-rated researchers in her institution. 